\title{
Production and Optimization for Performance and Emission Parameters of a CI-DI Engine Running on Mahua Biodiesel Blended with Mahua Oil
}

\author{
Ghaleppa B ${ }^{1}$, Rana Pratap Reddy N$^{2}$, Nikhil V Hoskoti ${ }^{3}$, Thilak Gowda A ${ }^{4}$, \\ Sanjay M Patil ${ }^{5}$, Rohit Bhat $\mathbf{H}^{6}$ \\ ${ }^{1}$ Assistant Professor, Mechanical Engineering, Global Academy of Technology, Bangalore, Karnataka \\ ${ }^{2}$ Professor, Mechanical Engineering, Global Academy of Technology, Bangalore, Karnataka \\ 3,4,5,6 UG - Mechanical Engineering, Global Academy of Technology, Bangalore, Karnataka
}

\begin{abstract}
Energy and foreign exchange crises are affecting countries without petroleum resources, owing mostly to crude petroleum imports. Alternative fuels that can be grown locally within the country from a range of resources, such as alcohol, biodiesel, vegetable oils, and so on, must be sought and identified. Sustainable development and environmental protection are the key motivations of alternative fuels. A viable alternative, biodiesel, solves all of the performance issues that come with diesel engines. Mahua oil was chosen as a source since it is non-edible, non-toxic, and biodegradable, as well as being widely available in India. Mahua Oil (MO) and its biodiesel are mixed in the samples (MOME). An acid and base trans-esterification process was used to make Mahua bio-diesel. No diesel oil was used to prepare samples for this experiment. Pure mahua oil, biodiesel, and gasoline samples had their physico-chemical properties investigated and compared to diesel. The goal of this study was to execute a performance and emission characteristics test with mahua biodiesel blended with Mahua Oil in various volume proportions (MO). Taguchi, Regression, and ANOVA analysis were used to tabulate and optimise the performance and emission outcomes.
\end{abstract}

Keywords: BSFC, BTE, CO Emissions, HC Emissions, $\mathrm{NO}_{\mathrm{x}}$ Emissions, Mahua Oil, Mahua Oil Methyl Ester (biodiesel), Optimization, Taguchi analysis and Transesterification.

Nomenclature-Mahua Oil (MO), Brake Thermal Efficiency (BTE), Brake Specific Fuel Consumption (BSFC), Hydrocarbons (HC), Nitrogen Oxides $\left(\mathrm{NO}_{\mathrm{x}}\right.$ ), Carbon Monoxide (CO), Signal-to-Noise ratio (SN ratio), Analysis of Variance (ANOVA), MB70 (Mahua Biodiesel 70\% + MO 30\% ), Mahua Biodiesel 100\% (MB100).

\section{INTRODUCTION}

The continual rise in fuel prices, as well as the rate of global warming, have prepared the path for biodiesel growth. The goal of this study is to reduce the carbon footprint of heavy-duty machinery like trucks, tractors, and ships, which are widely employed in farming, construction, and transportation. Electrifying or modifying the currently used CI engines is difficult due to the significant costs involved. The introduction of biodiesel, which can be used directly in CI engines without or with little engine modifications, makes biodiesel more cost-effective and environmentally friendly than diesel. The availability of wastelands can be used to grow a large number of non-edible oil seed crops, which will create jobs and enhance the economy. Mahua It has been discovered that biodiesel is more efficient than diesel. When compared to diesel, $\mathrm{CO}, \mathrm{HC}$, SOX, and $\mathrm{CO}$ emissions were reduced by $58,63,12$, and $70 \%$, respectively [1]. Butanol with $2 \% \mathrm{H} 2 \mathrm{SO} 4$ was shown to be a promising value, lowering acid $\%$ from $19.8 \%$ to $1.1 \%$. At $80{ }^{\circ} \mathrm{C}, 90$ minutes of chemical reaction time, and $500 \mathrm{rpm}$ stirring speed, the base esterification produced $94.8 \%$ biodiesel [2]. Direct usage of SVO in CI engines causes greater ignition delays due to the lower heating value. When SVO is used in an ICE instead of petrol or diesel, the temperature of the exhaust gas rises. SVO can be utilised in conjunction with biodiesel or diesel fuel [3]. The exhaust gas's temperature Maximum brake thermal efficiency, smallest brake specific fuel consumption, and lowest $\mathrm{HC}, \mathrm{CO}$, and smoke emissions were attained at IOP of 250bar for the B20 sample, but there was a little rise in NOX content [4]. A two-step trans-esterification process, such as acid fueled by base, yields more biodiesel. The amount of FFA in raw oil was lowered to less than $1 \%$. The acquired results are particularly impressive when compared to diesel [5]. The use of $15 \%$ mahua boosts thermal efficiency and increases SFC. The amount of smoke produced drops, but the amount of NOX produced remains the same when the engine is just partially loaded. As the additive composition and proportion rise, $\mathrm{CO}$ 


\section{DOI: $10.17148 /$ IARJSET.2021.81228}

emission increases somewhat [6]. The use of vegetable oil in the CI engine can cause technical problems if it is run for an extended period of time. SVO oil is a biodegradable, renewable fuel with a shorter carbon cycle and is environmentally benign. Heavy-duty vehicles can run on a mixture of mahua oil methyl ester and diesel. Increased biodiesel proportion in mixing reduces $\mathrm{HC}$ and $\mathrm{CO}$ emissions greatly, although nitrogen use and fuel consumption rise marginally when compared to diesel. Mahua biodiesel emits $4 \%$ fewer NOx, $26 \%$ fewer CO, and $20 \%$ fewer HC than diesel fuel. Practical evidence suggests that mahua methyl ester could be employed as an alternative fuel in diesel engines. Biodiesel made from Mahua oil has the potential to be a long-term fuel source. For B20 (20\% biodiesel+80\% diesel), CO and $\mathrm{HC}$ dropped by $20.84 \%$ and $50 \%$, respectively. Sample B10 (10\% biodiesel+90\% diesel) reduced NOX by up to $22.1 \%$. Lower-blend fuels can be used as a long-term fuel in CI engines, boosting energy efficiency [7]. The usage of edible oil for biodiesel generation will have a negative impact on food security and biodiversity. The non-edible biodiesel has a greater brake thermal efficiency and a lower BSFC, although it has a minor rise in NOx emissions. As a result, it is concluded that non-edible-based bio-diesels should be regarded as a future fuel for diesel engines [8]. Without modifying the engine, non-edible straight vegetable oil-diesel with $20 \%$ volume concentrations can be used in petroleum-based diesel engines. In comparison to conventional results, the data show that BTE is lower and BSFC is higher. It was also discovered that burning warmed mahua oil enhances efficiency and reduces emissions. When mahua oil is heated to 90 degrees Celsius, it loses viscosity, enhances BTE, and reduces pollutants [9]. Using the Taguchi approach, this research attempts to improve the performance and emission characteristics of Karanja oil methyl ester. For each emission and performance parameter BSFC, BTHE, CO, HC, NOX, and smoke, the input parameters Load, mix, compression ratio, injection pressure, and injection duration in degrees are optimised using their corresponding $\mathrm{S} / \mathrm{N}$ ratios. The noise, performance, and emission aspects of a diesel-powered CI engine were studied using the Taguchi method. Mahua oil and diesel mixes were evaluated and optimised for BSFC in a diesel engine. The Taguchi technique was used to assess the control factors injection pressure, mix, and load at four levels in an L16 array. The average output and S/N ratios at each level were obtained using S/N ratios and means plots, which helped find the best BSFC condition. The Taguchi method was then used to calculate the BSFC value at the optimum condition, which was found to be $0.27625 \mathrm{Kg} / \mathrm{Kwh}$ at $160 \mathrm{bar}$ injection pressure, $0 \%$ blend, and $10 \%$ engine load [10].

All previous relevant efforts in this sector blend diesel with biodiesel, however this study focuses on removing the use of diesel and replacing it with a mahua oil-biodiesel blend. The engine specifications are then tweaked to achieve desired performance and pollution levels.

\section{EXPERIMENTAL METHODS OR METHODOLOGY}

2.1 Filtration and Preheat: The raw Mahua Oil (MO) is filtered and heated to $90^{\circ} \mathrm{C}$ to remove any water, moisture and contaminants.

2.2 Two-step transesterification: The acid esterification procedure is performed on the preheated MO. In a 2000 $\mathrm{ml}$ beaker, a $500 \mathrm{~mL}$ oil, $175(0.35 \mathrm{v} / \mathrm{v})$ methanol, and $5 \mathrm{~mL}$ concentrated sulphuric acid mixture was placed on a hot plate magnetic stirrer. For 60 minutes, the reaction was kept at a temperature of $50^{\circ} \mathrm{C}$ and a speed of $450 \mathrm{RPM}$. In a separating funnel, the solution was left to layer separate for roughly 12 hours. The top layer of oil separated from the high-density glycerin. The acid esterification product, $125 \mathrm{ml}$ of methanol, and $0.7 \% \mathrm{KOH}(3.5 \mathrm{~g})$ as the catalyst are mixed with the first step acid reaction solution and placed on a stirrer for 1 hour at $50^{\circ} \mathrm{c}$ and 450 RPM. For around 12 hours, the mixture was allowed to separate. The top layer is water washed twice at $50^{\circ} \mathrm{C}$ by strongly mixing with water and allowing to separate for about 5 hours. The resulting top layer is glycerin-free and is used to make fuel.

2.3 Fuel samples preparation: MB100 (100\% MB+0 \% MO), MB90 (90\% MB+10\% MO), MB80 (80\% MB+20 $\% \mathrm{MO})$, and MB70 (70 \% MB+30\% MO) test fuels were generated on a volumetric basis. TABLE 1 shows the test findings for the above substances, which were determined and compared to diesel.

TABLE 1: Properties of test fuels

\begin{tabular}{|l|l|l|l|l|}
\hline PROPERTIES & $\begin{array}{l}\text { Fire Point } \\
{ }^{\circ} \mathbf{C}\end{array}$ & $\begin{array}{l}\text { Density } \\
(\mathbf{k g} / \mathbf{m 3})\end{array}$ & $\begin{array}{l}\text { Kinematic } \\
\text { Viscosity }(\mathbf{c S t})\end{array}$ & $\begin{array}{l}\text { Calorific value } \\
(\mathbf{K J} / \mathbf{k g})\end{array}$ \\
\hline $\begin{array}{l}\text { Mahua Oil } \\
\text { (MO) }\end{array}$ & 270 & 916 & 35.03 & 38325 \\
\hline MB70 & 175 & 856 & 12.09 & 43290 \\
\hline MB80 & 165 & 853 & 7.11 & 43500 \\
\hline MB90 & 160 & 850 & 5.9 & 43693 \\
\hline $\begin{array}{l}\text { MB100 } \\
\text { (MOME) }\end{array}$ & 150 & 845 & 3.6 & 43840 \\
\hline Diesel & 52 & 814 & 2.89 & 44296 \\
\hline
\end{tabular}

2.4 Engine performance: In this experiment, a Kirloskar 4 stroke engine with water cooling, electrical resistance, constant speed of $1500 \mathrm{RPM}$, and $5.2 \mathrm{~kW}$ output power was employed, and the characteristics are listed in TABLE 2. 


\section{International Advanced Research Journal in Science, Engineering and Technology}

\section{Vol. 8, Issue 12, December 2021}

\section{DOI: $10.17148 /$ IARJSET.2021.81228}

The engine was connected to a computerized system that tracked fuel usage and thermal efficiency. To warm up the engine, regular diesel fuel was utilised at first, and a gas analyzer was employed to measure the exhaust gas emissions.

TABLE 2: Test Engine Specifications

\begin{tabular}{|l|l|}
\hline $\begin{array}{l}\text { Engine } \\
\text { Manufacturer }\end{array}$ & $\begin{array}{l}\text { Kirloskar, rated power on TV1 single cylinder, stationary } \\
\text { diesel engine }\end{array}$ \\
\hline Engine type & Engine with four strokes and a water cooling system \\
\hline Bore and stroke & 87.5 and $110 \mathrm{~mm}$ \\
\hline $\begin{array}{l}\text { Engine } \\
\text { displacement }\end{array}$ & $661 \mathrm{cc}$ \\
\hline $\begin{array}{l}\text { Maximum power } \\
\text { and speed }\end{array}$ & $5.2 \mathrm{~kW}$ at speed $1500 \mathrm{RPM}$ \\
\hline Compression Ratio & $17.5: 1$ \\
\hline Starting & $\mathrm{Cranking}$ \\
\hline Injection pressure & $120-140 \mathrm{Kg} / \mathrm{cm}^{2}$ \\
\hline Emission Gases & $\mathrm{HC}, \mathrm{CO}, \mathrm{NO}_{\mathrm{X}}$ \\
\hline
\end{tabular}

\subsection{Optimization:}

2.5.1 Taguchi analysis: To examine the optimization of performance and emission characteristics for mahua biodiesel blends and to discover the optimum operating condition for each parameter, the Taguchi technique was utilised. Using the Minitab software, an L16 orthogonal array was chosen for the analysis. Two factors were examined at four levels in this study, as shown in TABLE 3. As shown in TABLE 4, the input parameters were blend (\% of biodiesel) and load, the performance parameters were BTE and BSFC, and the emission parameters were HC, CO, and NOx. Each experiment's $\mathrm{SN}$ ratios are calculated and plotted, and they're utilised to find the best condition for a parameter. The highest $\mathrm{S} / \mathrm{N}$ ratio is the best state for a parameter. The $\mathrm{S} / \mathrm{N}$ ratios are calculated using any of the three conditions. For parameters that are favourable and should be maximized. In this case, the larger the better is used. For the characteristics that are undesired or are worthless byproducts and should be minimized, the smaller the better condition is used. The smaller the better, was used to examine BSFC, HC, CO, and NOx. For parameters that are desired only within a given range of values and must be constrained inside that range of values, nominal is the better condition.

Larger is better $-\mathrm{S} / \mathrm{N}$ ratio $=-10 \log _{10}\left[\frac{\operatorname{sum}\left(\frac{1}{\mathrm{y}^{2}}\right)}{\mathrm{n}}\right]$

Smaller is better $-\mathrm{S} / \mathrm{N}$ ratio $=-10 \log _{10}\left[\frac{\operatorname{sum}\left(\mathrm{y}^{\wedge} 2\right)}{\mathrm{n}}\right]$

Nominal is best $-\mathrm{S} / \mathrm{N}$ ratio $=-10 \log _{10}\left(\mathrm{~s}^{2}\right)$

TABLE 3: Data inputs given in Minitab for Taguchi analysis

\begin{tabular}{|l|l|l|}
\hline Parameters & Blend (\%) & Load (\%) \\
\hline Level 1 & 100 & 25 \\
\hline Level 2 & 90 & 50 \\
\hline Level 3 & 80 & 75 \\
\hline Level 4 & 70 & 100 \\
\hline
\end{tabular}

TABLE 4: Response input table

\begin{tabular}{|l|l|l|l|l|l|l|l|}
\hline SI. No. & Blend $(\boldsymbol{\%})$ & Load $(\boldsymbol{\%})$ & BTE $(\boldsymbol{\%})$ & BSFC (kg/KW-min) & HC $(\mathbf{p p m})$ & CO $(\mathbf{p p m})$ & NOx $(\mathbf{p p m})$ \\
\hline 1 & 100 & 25 & 17.44 & 0.0038 & 10 & 0.06 & 219 \\
\hline 2 & 100 & 50 & 3.49 & 0.0037 & 19 & 0.07 & 249 \\
\hline 3 & 100 & 75 & 30.78 & 0.0037 & 22 & 0.06 & 271 \\
\hline 4 & 100 & 100 & 37.58 & 0.0031 & 29 & 0.06 & 298 \\
\hline 5 & 90 & 25 & 17.73 & 0.0046 & 21 & 0.07 & 187 \\
\hline 6 & 90 & 50 & 6.72 & 0.0044 & 27 & 0.08 & 201 \\
\hline 7 & 90 & 75 & 30.89 & 0.0041 & 31 & 0.09 & 290 \\
\hline 8 & 90 & 100 & 37.31 & 0.0039 & 36 & 0.10 & 329 \\
\hline 9 & 80 & 25 & 17.54 & 0.0044 & 25 & 0.09 & 198 \\
\hline 10 & 80 & 50 & 29.96 & 0.0041 & 23 & 0.09 & 271 \\
\hline 11 & 80 & 75 & 34.56 & 0.0037 & 27 & 0.09 & 321 \\
\hline 12 & 80 & 100 & 41.27 & 0.0033 & 27 & 0.09 & 386 \\
\hline
\end{tabular}


IARJSET

Vol. 8, Issue 12, December 2021

DOI: $10.17148 / I A R J S E T .2021 .81228$

\begin{tabular}{|l|l|l|l|l|l|l|l|}
\hline 13 & 70 & 25 & 2.35 & 0.0049 & 30 & 0.12 & 220 \\
\hline 14 & 70 & 50 & 29.74 & 0.0046 & 35 & 0.11 & 281 \\
\hline 15 & 70 & 75 & 33.43 & 0.0041 & 27 & 0.08 & 305 \\
\hline 16 & 70 & 100 & 39.69 & 0.0036 & 28 & 0.06 & 354 \\
\hline
\end{tabular}

2.5.2 Regression analysis: Multiple regression is a statistical strategy for relating important continuous predictors to responses. The regression equations and coefficients aid in determining how each response is affected by all of the variables.

\section{RESULTS AND DISCUSSION}

3.1 BTE: BTE was determined to be maximum for $80 \%$ blend and $100 \%$ load when the Taguchi method was employed to analyse the $\mathrm{S} / \mathrm{N}$ curves. The BTE was affected more by the load than by the blend. The regression equation for BTE is shown below, which shows the relationship between BTE and parameters.

$\mathrm{BTE}=19.7$ - 0.196 Blend + 0.3621 Load.

It has been discovered that load has a greater impact on BTE than blend. The regression model analysis yielded the fitted linear curve of BTE shown below.
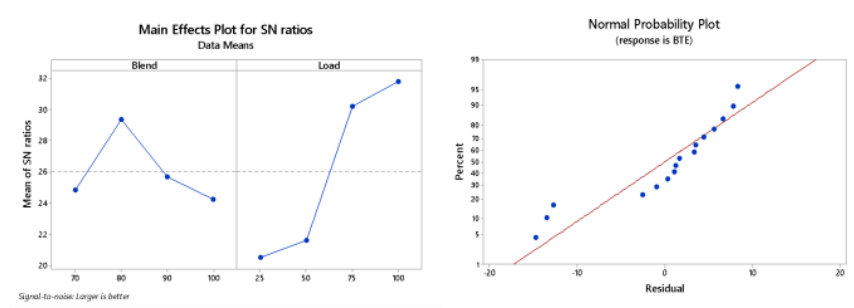

Fig 1. SN Ratio and NPP for BTE (Larger is better)
TABLE 5: Analysis of Variance Tables for BTE vs Blend, Load

\begin{tabular}{|l|l|l|}
\hline Source & DF & Contribution \\
\hline Blend & 3 & $7.02 \%$ \\
\hline Load & 3 & $67.97 \%$ \\
\hline Error & 9 & $25.01 \%$ \\
\hline Total & $\mathbf{1 5}$ & $\mathbf{1 0 0 . 0 0 \%}$ \\
\hline
\end{tabular}

3.2 BSFC: According to Taguchi analysis, the best conditions for BSFC were $100 \%$ blend and $100 \%$ load. The load on BSFC was shown to have a greater impact than blend. The following equation was used in the regression model to link the BSFC with the input parameters.

$\mathrm{BSFC}=0.006318-0.000018$ Blend -0.000013 Load.

The load has more control over BSFC, according to the regression model. The fitted linear curve of BSFC is shown in the diagram below.
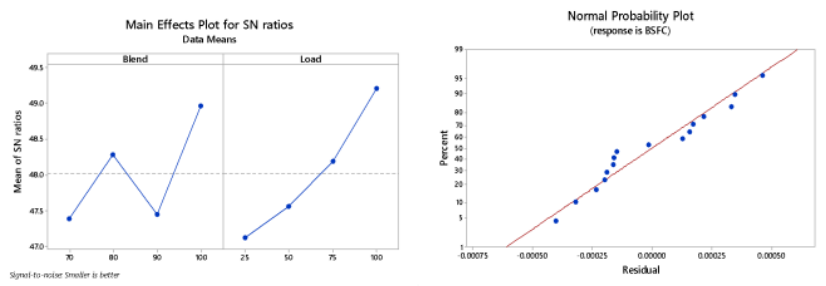

Fig 2. SN Ratio and NPP for BSFC (Smaller is better)

TABLE 6: Analysis of Variance Tables for BSFC vs Blend, Load

\begin{tabular}{|l|l|l|}
\hline Source & DF & Contribution \\
\hline Blend & 3 & $38.11 \%$ \\
\hline Load & 3 & $55.33 \%$ \\
\hline Error & 9 & $6.56 \%$ \\
\hline Total & $\mathbf{1 5}$ & $\mathbf{1 0 0 . 0 0 \%}$ \\
\hline
\end{tabular}

3.3 HC: Taguchi research revealed that the optimum HC condition is $100 \%$ blend and $25 \%$ load. The blend was shown to have a greater impact on $\mathrm{HC}$ emissions than the load. The following equation was used in the regression model to link the $\mathrm{HC}$ and the input parameters.

$\mathrm{HC}=42.24-0.268$ Blend +0.1050 Load.

The blend was discovered to have a greater impact on HC emissions. The fitted linear curve of HC is shown in the diagram below.
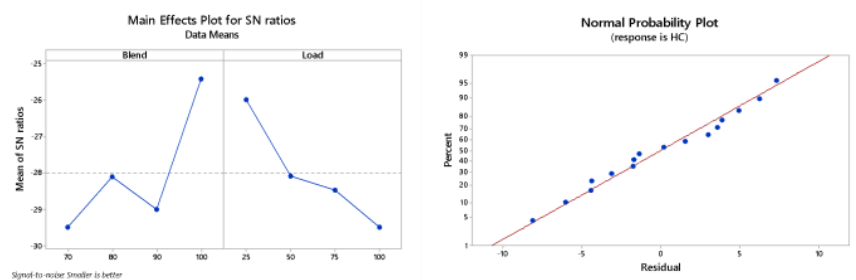

TABLE 7: Analysis of Variance Tables for HC vs Blend, Load

Fig 3. SN Ratio and NPP for HC (Smaller is better)

\begin{tabular}{|l|l|l|}
\hline Source & DF & Contribution \\
\hline Blend & 3 & $40.20 \%$ \\
\hline Load & 3 & $24.74 \%$ \\
\hline Error & 9 & $35.06 \%$ \\
\hline Total & $\mathbf{1 5}$ & $\mathbf{1 0 0 . 0 0 \%}$ \\
\hline
\end{tabular}




\title{
International Advanced Research Journal in Science, Engineering and Technology
}

\author{
Vol. 8, Issue 12, December 2021
}

\section{DOI: $10.17148 / I A R J S E T .2021 .81228$}

3.4 CO: For CO, a mix of $100 \%$ and a load of $100 \%$ was determined to be optimal. CO emissions are better controlled with the blend. During the regression analysis, the following relationship between CO and input parameters was discovered.

$\mathrm{CO}=0.1699-0.000950$ Blend -0.000100 Load.

It was discovered that the blend had a stronger impact on CO emissions. CO regression analysis yielded the following fitted linear curve.
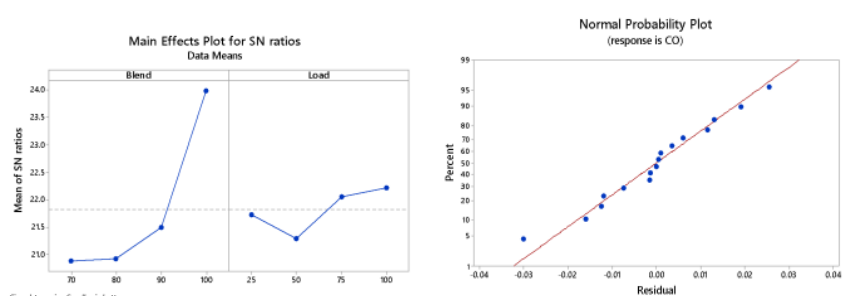

TABLE 8: Analysis of Variance Tables for CO vs Blend, Load

\begin{tabular}{|l|l|l|}
\hline Source & DF & Contribution \\
\hline Blend & 3 & $45.36 \%$ \\
\hline Load & 3 & $3.98 \%$ \\
\hline Error & 9 & $50.66 \%$ \\
\hline Total & $\mathbf{1 5}$ & $\mathbf{1 0 0 . 0 0 \%}$ \\
\hline
\end{tabular}

Fig 4. SN Ratio and NPP for CO (Smaller is better)

3.5 NOx: Using the Taguchi analysis, the optimum condition for NOx was shown to be a blend of $100 \%$ and $25 \%$ load. NOx emissions were shown to be more affected by the load. The following equation was used in the regression model to link the BSFC with the input parameters.

$\mathrm{NOx}=274.7-1.345$ Blend + 1.814 Load.

The load was discovered to have a bigger impact on NOx emissions. Regression study of NOx yielded the following fitter linear curve.
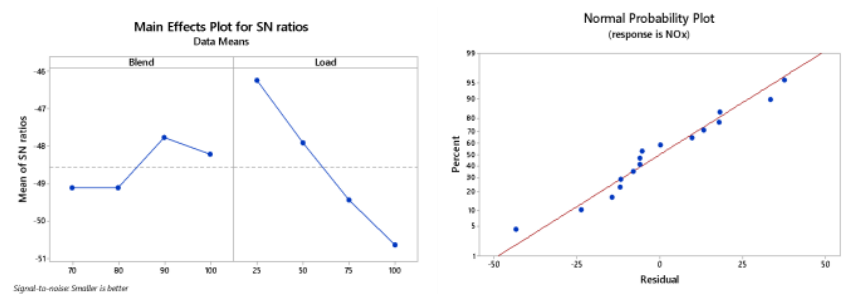

TABLE 9: Analysis of Variance Tables for $\mathrm{NO}_{\mathrm{X}}$ vs Blend, Load

\begin{tabular}{|l|l|l|}
\hline Source & DF & Contribution \\
\hline Blend & 3 & $10.67 \%$ \\
\hline Load & 3 & $80.22 \%$ \\
\hline Error & 9 & $9.11 \%$ \\
\hline Total & $\mathbf{1 5}$ & $\mathbf{1 0 0 . 0 0 \%}$ \\
\hline
\end{tabular}

Fig 5. SN Ratio and NPP for $\mathrm{NO}_{\mathrm{X}}($ Smaller is better)

\section{CONCLUSION}

The research in various articles focused on a diesel engine that was run on pure biodiesel and biodiesel combined with diesel. There was no serious attempt to use raw oil, a mixture of straight vegetable oil and its biodiesel (methyl ester) as a diesel engine fuel. The properties of Mahua Oil (MO), Mahua Oil Methyl Ester (biodiesel), and their blends (without using diesel) were evaluated, and the findings were compared to diesel. The results were within the acceptable range. All prepared samples had a better brake thermal efficiency than diesel. The Taguchi method and regression analysis were used to optimise the performance and emission parameters in this experimental study. The effects of variables like blend and load have been thoroughly investigated, and their interactions have been plotted, analysed, and described above. The contributions of blend and load on BTE were 7.02\% and 67.97\%. Blend and load each contributed $7.02 \%$ and $67.97 \%$ to BTE, respectively. Blend and load each contributed $38.11 \%$ and $55.33 \%$ to the BSFC, respectively. On HC, blend and load contributed $40.20 \%$ and $24.74 \%$, respectively. Blend and load each contributed $45.36 \%$ and $3.98 \%$ of CO, respectively. Blend and load each contributed $10.67 \%$ and $80.22 \%$ of NOX, respectively.

\section{REFERENCES}

[1] S. Puhan, N. Vedaraman, G. Sankaranarayanan, and B. V. B. Ram, "Performance and emission study of Mahua oil (madhuca indica oil) ethyl ester in a 4-stroke natural aspirated direct injection diesel engine," Renew. Energy, vol. 30, no. 8, pp. 1269-1278, 2005, doi: 10.1016/j.renene.2004.09.010.

[2] R. Sathish Kumar and A. Krupa Vara Prasad, "Environment friendly butyl ester biodiesel production from mahua oil: optimization and characterization," SN Appl. Sci., vol. 1, no. 8, 2019, doi: 10.1007/s42452-019-0913-6.

[3] A. Mahalingam, Y. Devarajan, S. Radhakrishnan, S. Vellaiyan, and B. Nagappan, "Emissions analysis on mahua oil biodiesel and higher alcohol blends in diesel engine," Alexandria Eng. J., vol. 57, no. 4, pp. 2627-2631, 2018, doi: 10.1016/j.aej.2017.07.009.

[4] A. Syed, S. A. P. Quadri, G. A. P. Rao, and W. Mohd, "Experimental investigations on DI (direct injection) diesel engine operated on dual fuel mode with hydrogen and mahua oil methyl ester (MOME) as injected fuels and effects of injection opening pressure," Appl. Therm. Eng., vol. 114, pp. 118-129, 2017, doi: 10.1016/j.applthermaleng.2016.11.152.

[5] M. Vijay Kumar, A. Veeresh Babu, and P. Ravi Kumar, "Producing biodiesel from crude Mahua oil by two steps of transesterification process," Aust. J. Mech. Eng., vol. 17, no. 1, pp. 2-7, 2019, doi: 10.1080/14484846.2017.1412243.

[6] P. R. Babu, K. P. Rao, and B. V. A. Rao, "The Role of Oxygenated Fuel Additive ( DEE ) along with Mahuva Methyl Ester to Estimate Performance and Emission analysis of DI-Diesel Engine," Int. J. Therm. Technol., vol. 2, no. 1, pp. 119-123, 2012, [Online]. Available: 


\section{IARJSET}

International Advanced Research Journal in Science, Engineering and Technology

Vol. 8, Issue 12, December 2021

\section{DOI: 10.17148/IARJSET.2021.81228}

https://inpressco.com/wp-content/uploads/2012/03/Paper1119-123.pdf.

[7] S. Kumar, S. Kumar, A. Kumar, S. Maurya, and V. Deswal, "Experimental investigation of the influence of blending on engine emissions of the diesel engine fueled by mahua biodiesel oil," Energy Sources, Part A Recover. Util. Environ. Eff., vol. 40, no. 8, pp. 994-998, 2018, doi: $10.1080 / 15567036.2018 .1468511$.

[8] A. M. Ashraful et al., "Production and comparison of fuel properties, engine performance, and emission characteristics of biodiesel from various non-edible vegetable oils: A review," Energy Convers. Manag., vol. 80, pp. 202-228, 2014, doi: 10.1016/j.enconman.2014.01.037.

[9] Sonar, Deepesh, S. L. Soni, Dilip Sharma, Anmesh Srivastava, and Rahul Goyal. 2015. "Performance and Emission Characteristics of a Diesel Engine with Varying Injection Pressure and Fuelled with Raw Mahua Oil (Preheated and Blends) and Mahua Oil Methyl Ester.” Clean Technologies and Environmental Policy 17(6):1499-1511. doi: 10.1007/s10098-014-0874-9.

[10] Nirav H. Rathod, Gaurav R. Rathod, Tushar M. Patel. 2015. "Parametric optimization of single cylinder CI engine for specific fuel consumption using mahua oil blend." IOSR Journal of Mechanical and Civil Engineering, e-ISSN: 2278-1684, p-ISSN: 2320-334X, Volume 12, Issue 2 Ver. IV (Mar - Apr. 2015), PP 28-33 